\title{
EXTENSIONS OF QUADRATIC TRANSFORMATION IDENTITIES FOR HYPERGEOMETRIC FUNCTIONS
}

\author{
Song-Liang QiU, XiaO-Yan Ma And Yu-Ming ChU*
}

Abstract. In the article, we extend the identities $F_{0}(x)=(1+r) F_{0}(r), 2 F_{0}(\sqrt{1-x})=(1+$ $r) F_{0}\left(1-r^{2}\right), 2 \bar{F}_{0}(y)=\sqrt{1+3 r} \bar{F}_{0}\left(1-r^{2}\right)$ and $\bar{F}_{0}(1-y)=\sqrt{1+3 r} \bar{F}_{0}\left(r^{2}\right)$ for hypergeometric functions $F_{0}(r)={ }_{2} F_{1}(1 / 2,1 ; 3 / 2 ; r)$ and $\bar{F}_{0}(r)={ }_{2} F_{1}(1 / 4,3 / 4 ; 1 ; r)$, performed by the quadratic transformations $r \mapsto x=4 r /(1+r)^{2}, r \mapsto \sqrt{1-x}, r \mapsto y=(1-r)^{2} /(1+3 r)^{2}$ and $r \mapsto 1-y$, to the zero-balanced hypergeometric function ${ }_{2} F_{1}(a, b ; a+b ; r)$, by showing new properties of ${ }_{2} F_{1}(a, b ; a+b ; r)$ and the Ramanujan type constant, and the monotonicity properties of certain combinations in terms of hypergeometric and elementary functions. These extensions give complete solutions of the problem of extending the transformation identities abovementioned to ${ }_{2} F_{1}(a, b ; a+b ; r)$, and perfect all the known related results. By these results, sharp transformation inequalities are obtained for the generalized Grötzsch ring function appearing in Ramanujan's modular equations.

Mathematics subject classification (2010): 33C05, 33F05, 30C62, 11F03.

Keywords and phrases: Zero-balanced hypergeometric function, quadratic transformation, generalized Grötzsch ring function, monotonicity, extension.

\section{REFERENCES}

[1] M. Abramowitz, I. A. Stegun, Handbook of Mathematical Functions with Formulas, Graphs, and Mathematical Tables, U. S. Government Printing Office, Washington, 1964.

[2] G. D. Anderson, S. L. Qiu, M. K. Vamanamurthy, M. Vuorinen, Generalized elliptic integrals and modular equations, Pacific J. Math. 192, 1 (2000), 1-37.

[3] G. D. Anderson, M. K. Vamanamurthy, M. Vuorinen, Conformal Invariants, Inequalities, and Quasiconformal Maps, John Wiley \& Sons, New York, 1997.

[4] G. E. Andrews, R. Askey, R. Roy, Special Functions, Cambridge Univversity Press, Cambridge, 1999.

[5] R. ASKeY, Ramanujan and hypergeometric and basic hypergeometric series, in: Ramanujan International Symposium on Analysis (Pune, 1987), 1-83, Macmillan of India, New Delhi, 1989.

[6] R. Askey, Handbooks of Special Functions, in: A century of Mathematics in America, Part III, 369-391, Hist. Math., 3, Amer. Math. Soc., Providence, RI, 1989.

[7] B. C. Berndt, Ramanujan's Notebooks, Part I, Springer-Verlag, New York, 1985.

[8] B. C. Berndt, Ramanujan's Notebooks, Part II, Springer-Verlag, New York, 1989.

[9] B. C. Berndt, Ramanujan's Notebooks, Part III, Springer-Verlag, New York, 1991.

[10] B. C. BERnd, Ramanujan's Notebooks, Part IV, Springer-Verlag, New York, 1994.

[11] B. C. Berndt, S. Bhargava, F. G. Garvan, Ramanujan's theories of elliptic functions to alternative bases, Trans. Amer. Math. Soc. 347, 11 (1995), 4163-4244.

[12] B. A. Bhayo, M. VuORinen, On generalized complete elliptic integrals and modular functions, Proc. Edinb Math. Soc. (2) 55, 3 (2012), 591-611.

[13] J. M. Borwein, P. B. Borwein, Pi and the AGM, John Wiley \& Sons, New York, 1987.

[14] J. M. Borwein, P. B. Borwein, A remarkable cubic mean iteration, in: Computational Methods and Function Theory, (Valparałso, 1989), 27-31, Springer, Berlin, 1990.

[15] B. C. Carlson, Special Functions of Applied Mathematics, Academic Press, New York, 1977. 
[16] Y.-M. CHU, Y.-F. QIU, M.-K. WANG, Hölder mean inequalities for the complete elliptic integrals, Integral Transforms Spec. Funct. 23, 7 (2012), 521-527.

[17] Y.-M. ChU, M.-K. WANG, Inequalities between arithmetic-geometric, Gini, and Toader means, Abstr. Appl. Anal. 2012 (2012), Article ID 830585, 11 pages.

[18] Y.-M. ChU, M.-K. WANG, Optimal Lehmer mean bounds for the Toader mean, Results Math. 61, 3-4 (2012), 223-229.

[19] Y.-M. ChU, M.-K. WAng, Y.-P. JiAnG, S.-L. QIU, Concavity of the complete elliptic integrals of the second kind with respect to Hölder means, J. Math. Anal. Appl. 395, 2 (2012), 637-642.

[20] Y.-M. ChU, M.-K. WANG, S.-L. QIU, Optimal combinations bounds of root-square and arithmetic means for Toader mean, Proc. Indian Acad. Sci. Math. Sci. 122, 1 (2012), 41-51.

[21] Y.-M. ChU, M.-K. WANG, S.-L. QIU, Y.-P. JIANG, Bounds for complete elliptic integrals of the second kind with applications, Comput. Math. Appl. 63, 7 (2012), 1177-1184.

[22] T.-R. HUANG, B.-W. HAN, X.-Y. MA AND Y.-M. CHU, Optimal bounds for the generalized EulerMascheroni constant, J. Inequal. Appl. 2018 (2018), Article 118, 9 pages.

[23] T.-R. Huang, S.-Y. TAN, X.-Y. MA, Y.-M. ChU, Monotonicity properties and bounds for the complete p-elliptic integrals, J. Inequal. Appl. 2018 (2018), Article 239, 11 pages.

[24] O. Lehto, K. I. VirTanen, Quasiconformal Mappings in the Plane, Springer-Verlag, New York, 1973.

[25] F. W. J. Olver, D. W. Lozier, R. F. Boisvert, C. W. Clark, NIST Handbook of Mathematical Functions, Cambridge University Press, Cambridge, 2010.

[26] S. Ponnus Amy, M. Vuorinen, Asymptotic expansions and inequalities for hypergeometric functions, Mathematika 44, 2 (1997), 278-301.

[27] W.-M. QIAN, Y.-M. CHU, Sharp bounds for a special quasi-arithmetic mean in terms of arithmetic and geometric means with two parameters, J. Inequal. Appl. 2017 (2017), Article 274, 10 pages.

[28] W.-M. QIAN, Z.-Y. HE, Y.-M. ChU, Approximation for the complete elliptic integral of the first kind, Exactas Fís. Nat. Ser. A Mat. RACSAM 114, 2 (2020), Article 57, 12 pages. https://doi.org/10.1007/s13398-020-00784-9

[29] S.-L. QIU, X.-Y. MA AND Y.-M. CHU, Sharp Landen transformation inequalities for hypergeometric functions, with applications, J. Math. Anal. Appl. 474, 2 (2019), 1306-1337.

[30] S.-L. QIU, X.-Y. MA, Y.-M. CHU, Transformation properties of hypergeometric functions and their applications, Available online at https://ef.msp.org/articles/uploads/aim/submitted/ 181128-SongliangQiu/181128-SongliangQiu-v1.pdf.

[31] S.-L. QIU, X.-Y. MA, T.-R. HuAng, Some properties of the difference between the Ramanujan constant and beta function, J. Math. Anal. Appl. 446, 1 (2017), 114-129.

[32] S.-L. QIU, M. VUORINEN, Landen inequalities for hypergeometric functions, Nagoya Math. J. 154 (1999), 31-56.

[33] S.-L. QIU, M. VUORINEN, Infinite products and normalized quotients of hypergeometric functions, SIAM J. Math. Anal. 30, 2 (1999), 1057-1075.

[34] S.-L. QIU, M. VUORINEn, Duplication inequalities for the ratios of hypergeometric functions, Forum Math. 12, 1 (2000), 109-133.

[35] S.-L. QIU, M. VuORINEN, Special function in geometric function theory, in: Handbook of Complex Analysis: Geometric Function Theory, Vol. 2, 621-659, Elsevier Sci. B. V., Amsterdam, 2005.

[36] J.-M. Shen, Z.-H. YANG, W.-M. QIAN, W. ZHANG, Y.-M. CHU, Sharp rational bounds for gamma function, Math. Inequal. Appl. 23, 3 (2020), 843-853.

[37] S. Simić, M. VuORINEN, Landen inequalities for zero-balanced hypergeometric functions, Abstr. Appl. Anal. 2012 (2012), Article ID 932061, 11 pages.

[38] M.-B.SUn, Y.-M. CHU, Inequalities for the generalized weighted mean values of $g$-convex functions with applications, Rev. R. Acad. Cienc. Exactas Fís. Nat. Ser. A Mat. RACSAM 114, 4 (2020), Article ID 172, 12 pages. https://doi.org/10.1007/s13398-020-00908-1

[39] M.-K. WANG, Y.-M. CHU, Refinements of transformation inequalities for zero-balanced hypergeometric functions, Acta Math. Sci. 37B, 3 (2017), 607-622.

[40] M.-K. WANG, Y.-M. CHU, Landen inequalities for a class of hypergeometric functions with applications, Math. Inequal. Appl. 21, 2 (2018), 521-537.

[41] M.-K. Wang, H.-H. Chu, Y.-M. Chu, Precise bounds for the weighted Hölder mean of the complete p-elliptic integrals, J. Math. Anal. Appl. 480, 2 (2019), Article ID 123388, 9 pages. https://doi.org/10.1016/j.jmaa.2019.123388 
[42] M.-K. WANG, Y.-M. CHU, Y.-P. JIANG, Ramanujan's cubic transformation inequalities for zerobalanced hypergeometric functions, Rocky Mountain J. Math. 46, 2 (2016), 679-691.

[43] M.-K. WAng, Y.-M. CHU, Y.-P. JiAng, D.-D. YAn, A class of quadratic transformation inequalities for zero-balanced hypergeometric functions, Acta Math. Sci. 34A, 4 (2014), 999-1007 (in Chinese).

[44] M.-K. WANG, H.-H. CHU, Y.-M. Li, Y.-M. CHU, Answers to three conjectures on convexity of three functions involving complete elliptic integrals of the first kind, Appl. Anal. Discrete Math. 14 (2020), $255-271$.

[45] M.-K. Wang, Y.-M. Chu, Y.-M. Li, W. ZHAng, Asymptotic expansion and bounds for complete elliptic integrals, Math. Inequal. Appl. 23, 3 (2020), 821-841.

[46] M.-K. WAng, Y.-M. CHU, S.-L. QIU, Y.-P. JiAng, Bounds for the perimeter of an ellipse, J. Approx. Theory 164, 7 (2012), 928-937.

[47] M.-K. Wang, Y.-M. ChU, Y.-F. QIU, S.-L. QIU, An optimal power mean inequality for the complete elliptic integrals, Appl. Math. Lett. 24, 6 (2011), 887-890.

[48] M.-K. WANG, Y.-M. CHU, Y. Q. Song, Ramanujan's cubic transformation and generalized modular equation, Sci. China Math. 58, 11 (2015), 2387-2404.

[49] M.-K. WANG, Y.-M. CHU AND W. ZhANG, Monotonicity and inequalities involving zero-balanced hypergeometric function, Math. Inequal. Appl. 22, 2 (2019), 601-617.

[50] M.-K. WANG, Y.-M. CHU, W. ZHANG, Precise estimates for the solution of Ramanujan's generalized modular equation, Ramanujan J. 49, 3 (2019), 653-668.

[51] M.-K. WANG, Z.-Y. HE, Y.-M. CHU, Sharp power mean inequalities for the generalized elliptic integral of the first kind, Comput. Methods Funct. Theory 20, 1 (2020), 111-124.

[52] M.-K. WANG, Y.-M. LI, Y.-M. CHU, Inequalities and infinite product formula for Ramanujan generalized modular equation function, Ramanujan J. 46, 1 (2018), 189-200.

[53] J.-L. WAng, W.-M. Qian, Z.-Y. HE, Y.-M. ChU, On approximating the Toader mean by other bivariate means, J. Funct. Spaces 2019 (2019), Article ID 6082413, 7 pages.

[54] M.-K. WANG, S.-L. QIU, Y.-M. CHU, Infinite series formula for Hübner upper bound function with applications to Hersch-Pfluger distortion function, Math. Inequal. Appl. 21, 3 (2018), 629-648.

[55] M.-K. WANG, S.-L. QIU, Y.-M. CHU, Y.-P. JiAng, Generalized Hersch-Pfluger distortion function and complete elliptic integrals, J. Math. Anal. Appl. 385, 1 (2012), 221-229.

[56] G.-D. WANG, X.-H. ZHANG, Y.-M. CHU, A power mean inequality for the Grötzsch ring function, Math. Inequal. Appl. 14, 4 (2011), 833-837.

[57] G.-D. WANG, X.-H. ZHANG, Y.-M. CHU, A power mean inequality involving the complete elliptic integrals, Rocky Mountain J. Math. 44, 5 (2014), 1661-1667.

[58] M.-K. WANG, W. ZHANG, Y.-M. CHU, Monotonicity, convexity and inequalities involving the generalized elliptic integrals, Acta Math. Sci., 39B, 5 (2019), 1440-1450.

[59] G.-D. WANG, X.-H. ZHANG, Y.-P. JiAnG, Concavity with respect to Hölder means involving the generalized Grötzsch function, J. Math. Anal. Appl. 379, 1 (2011), 200-204.

[60] Z.-H. YANG, Y.-M. CHU, A monotonicity property involving the generalized elliptic integral of the first kind, Math. Inequal. Appl. 20, 3 (2017), 729-735.

[61] Z.-H. YANG, Y.-M. CHU, M.-K. WANG, Monotonicity criterion for the quotient of power series with applications, J. Math. Anal. Appl. 428, 1 (2015), 587-604.

[62] Z.-H. YANG, Y.-M. CHU, W. ZHANG, High accuracy asymptotic bounds for the complete elliptic integral of the second kind, Appl. Math. Comput. 348 (2019), 552-564.

[63] Z.-H. YANG, W.-M. QIAN, Y.-M. CHU, Monotonicity properties and bounds involving the complete elliptic integrals of the first kind, Math. Inequal. Appl. 21, 4 (2018), 1185-1199.

[64] Z.-H. YANG, W.-M. QIAN, Y.-M. CHU, W. ZHANG, Monotonicity rule for the quotient of two functions and its application, J. Inequal. Appl. 2017 (2017), Article 106, 13 pages.

[65] Z.-H. YANG, W.-M. QiAn, Y.-M. CHU, W. ZHANG, On rational bounds for the gamma function, J. Inequal. Appl. 2017, (2017), Article 210, 17 pages.

[66] Z.-H. YANG, W.-M. QIAN, Y.-M. CHU, W. ZHANG,, On approximating the arithmetic-geometric mean and complete elliptic integral of the first kind, J. Math. Anal. Appl. 462, 2 (2018), 1714-1726.

[67] Z.-H. YAnG, W.-M. QIAN, W. ZhanG, Y.-M. CHU, Notes on the complete elliptic integral of the first kind, Math. Inequal. Appl. 23, 1 (2020), 77-93.

[68] Z.-H. YAnG, W. ZHANG, Y.-M. CHU, Sharp Gautschi inequality for parameter $0<p<1$ with applications, Math. Inequal. Appl. 20, 4 (2017), 1107-1120. 
[69] X.-H. Zhang, G.-D. Wang, Y. M. Chu, Some inequalities for the generalized Grötzsch function, Proc. Edinb. Math. Soc. (2) 51, 1 (2008), 265-272.

[70] T.-H. ZHAO, Y.-M. CHU, H. WANG, Logarithmically complete monotonicity properties relating to the gamma function, Abstr. Appl. Anal. 2011 (2011), Article ID 896483, 13 pages.

[71] T.-H. ZHAO, L. SHI, Y.-M. CHU, Convexity and concavity of the modified Bessel functions of the first kind with respect to Hölder means, Rev. R. Acad. Cienc. Exactas Fís. Nat. Ser. A Mat. RACSAM 114, 2 (2020), Article 96, 14 pages. https://doi.org/10.1007/s13398-020-00825-3

[72] T.-H. ZHAO, M.-K. WANG, Y.-M. CHU, A sharp double inequality involving generalized complete elliptic integral of the first kind, AIMS Math. 5, 5 (2020), 4512-4528.

[73] T.-H. ZHAO, M.-K. WANG, W. ZHANG, Y.-M. CHU, Quadratic transformation inequalities for Gaussian hypergeometric function, J. Inequal. Appl. 2018 (2018), Article 251, 15 pages.

[74] T.-H.ZHAO, B.-C. ZHOU, M.-K. WANG, Y.-M. CHU, On approximating the quasi-arithmetic mean, J. Inequal. Appl. 2019 (2019), Article 42, 12 pages. 